\title{
ON THE DIMENSIONS OF LARGE INDUCTANCE COILS.
}

By James E. Ives.

$\mathrm{T}^{\mathrm{T}}$ is sometimes desired to construct large coils of known self inductance. Having recently had occasion to calculate the inductance of a number of such coils, I have thought it desirable to record the results.

The inductance of a coil of rectangular cross-section may be calculated, to about one per cent., from Maxwell's formula:

$$
\begin{aligned}
& L=4 \pi a n^{2}\left[\log _{e} \frac{8 a}{r}+\frac{1}{12}-\frac{4}{3}\left(\theta-\frac{\pi}{4}\right) \cot 2 \theta\right. \\
& \left.-\frac{1}{3} \pi \operatorname{cosec} 2 \theta-\frac{1}{6} \cot ^{2} \theta \log _{e} \cos \theta-\frac{1}{6} \tan ^{2} \theta \log _{\ominus} \sin \theta\right]
\end{aligned}
$$

where (see figure)

$L=$ inductance of coil,

$a=$ mean radius of coil,

$n=$ number of turns in coil,

$r=$ diagonal of the cross-section,

$\theta=$ angle made by diagonal with lower edge of the cross-section.

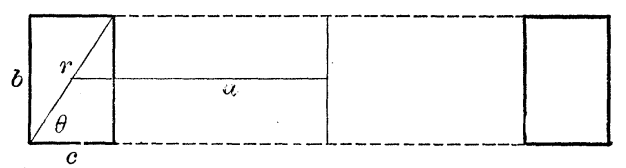

Fig. 1.

In this formula only the first term of a series is used. If greater accuracy is required the second term must be added. ${ }^{1}$

This expression may be written in the form

$$
L=4 \pi a n^{2}\left[\log _{e} \frac{8 a}{r}-f(\theta)\right]
$$

1 See Physical Review, Vol. XIV., p. 297, 1902. 
where $f(\theta)$ is a term depending only upon the shape of the crosssection. For a square cross-section, $f(\theta)=.83$. For a cross-section in which $\theta=73^{\circ}, f(\theta)=.72$.

The inductances of seven coils of varying dimensions, constructed with No. $18^{1}$ (Brown and Sharpe gauge) copper wire, were calculated by this formula, and the results are given in the accompanying table. The wire was double cotton covered, and the centers of the wires were assumed to be one twentieth of an inch apart. Coils I.-VI. were wound with 5,000 feet of wire, and coil VII. with Io,000 feet. Only two values of $\theta$ were used, viz., $\theta=45^{\circ}$ and $\theta=73^{\circ}$. It may be noted, that for the same $\theta$, the cross-sections, though not all of the same size, are all similar. Coils III. and VII. have the dimensions for maximum inductance for 5,000 and I0,000 feet, respectively, of No. I 8 wire. The dimensions of a coil of maximum inductance for a given length of wire are found by taking $\frac{2 a}{b}=3 \cdot 7$, where $a$ is the mean radius of the coil, and $\dot{b}$ is the length of a side of the square cross-section. ${ }^{2}$

TABLE I.

\begin{tabular}{|c|c|c|c|c|c|c|c|c|}
\hline & 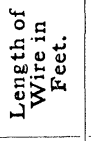 & 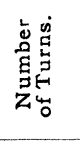 & 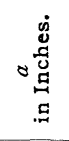 & 离 & 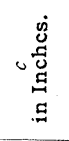 & $\theta$ & 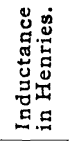 & Remarks. \\
\hline I. & 5,000 & 2625 & 3.13 & 2.75 & 2.75 & $45^{\circ}$ & .72 & \\
\hline II. & 5,000 & 2625 & 3.75 & 5.00 & 1.50 & $73^{\circ}$ & .85 & \\
\hline III. & 5,000 & 2230 & 4.36 & 2.36 & 2.36 & $45^{\circ}$ & 1.05 & Maximum for 5,000 feet. \\
\hline IV. & 5,000 & 2230 & 4.36 & 4.30 & 1.29 & $73^{\circ}$ & .92 & \\
\hline V. & 5,000 & 1940 & 5.00 & 2.20 & 2.20 & $45^{\circ}$ & 1.04 & \\
\hline VI. & 5,000 & 1940 & 5.00 & 4.00 & 1.20 & $73^{\circ}$ & .93 & \\
\hline VII. & 10,000 & 3530 & 5.50 & 2.97 & 2.97 & $45^{\circ}$ & 3.33 & Maximum for 10,000 feet. \\
\hline
\end{tabular}

From the values given in the table it is evident:

I. That a coil of maximum inductance must have a square crosssection.

2. That the inductance of a coil, with a given length of wire, increases rapidly, as the mean radius is increased, up to the maxi-

1 No. 18 wire has a diameter of .0403 inch.

${ }^{2}$ See Maxwell, Electricity and Magnetism, $z 706$. 
mum inductance, and then, as the mean radius is increased still further, decreases very slowly. Therefore it is better to make the mean radius too great than too small.

3. That for coils of maximum inductance, the inductance increases very rapidly as the length of wire used increases; not quite as fast as the square of the length.

UnIVERSITY oF CinCINNATI,

October, 1902. 